\title{
A Comparative Pathophysiological Study of Normal and Growth Retarded Human Placental Tissue
}

\author{
Adam Moyosore Afodun, ${ }^{1}$ Khadijat Kofoworola Quadri, ${ }^{2}$ Mustapha Akajewole Masud, ${ }^{1}$ \\ Oluseyi Abimbola Ogunsola, ${ }^{2}$ Abdurrasheed Ola Muhammad, ${ }^{3}$ \\ Rafiu Abioye Ajiboye, ${ }^{4}$ and Eziekel Ademola Caxton-Martins ${ }^{5}$
}

${ }^{1}$ Department of Anatomy, Faculty of Basic Medical Sciences, University of Ilorin, PMB 1515, Ilorin 240003, Nigeria

${ }^{2}$ Department of Physiology, College of Medicine, University of Lagos, PMB 2003, Lagos 220001, Nigeria

${ }^{3}$ Histopathology Unit, Pathology Department, University of Ilorin Teaching Hospital, PMB 1459, Ilorin 240003, Nigeria

${ }^{4}$ Department of Obstetrics and Gynaecology, College of Medicine, University of Lagos, PMB 2003, Idi-Araba, Lagos 220001, Nigeria

${ }^{5}$ Department of Anatomy and Cell Biology, Faculty of Basic Medical Sciences, Obafemi Awolowo University, PMB 5545, Ile-Ife 220005, Nigeria

Correspondence should be addressed to Adam Moyosore Afodun; afodunadam@yahoo.com

Received 17 December 2013; Revised 27 March 2014; Accepted 7 April 2014; Published 11 May 2014

Academic Editor: Sharon DeMorrow

Copyright (c) 2014 Adam Moyosore Afodun et al. This is an open access article distributed under the Creative Commons Attribution License, which permits unrestricted use, distribution, and reproduction in any medium, provided the original work is properly cited.

\begin{abstract}
This study compares the pathophysiology of normal and growth retarded human placental tissues. Female patients were recruited from the Antenatal Clinic of Dolu Specialist Hospital, Mafoluku, Oshodi, Lagos, between 2008 and 2012. A total of 48 normal term placentas and 15 placentas of known IUGR cases were used for this study. IUGR cases were confirmed on the basis of ultrasound follow-up and diagnosis. Normal term placentas were collected at the point of delivery by a consultant gynaecologist, the cords were clamped, and membranes were then carefully trimmed after which each placenta was weighed. About $1 \mathrm{~cm}$ thickness of both normal and growth retarded placenta tissues was cut, processed for hematoxylin and eosin stain, while tissues for enzyme (ALP) assay were homogenized in cold $0.5 \mathrm{M}$ sucrose solution. Comparative analysis of the data was done using ANOVA; $P<0.05$ was taken as significant. The photomicrographs were observed/studied under light microscope, using the X150 and X600 magnifications. It was revealed therein that placental tissues are homogenous (regionally), compromised of maternal spiral arterioles and deregulated villous vasculogenesis, and that there is a significant difference in the level of alkaline phosphatase enzyme. We therefore concluded that there is a distinct difference between the normal and growth retarded human placenta tissue.
\end{abstract}

\section{Introduction}

Human placenta, materno-fetal organ, binds two genetically distinct individuals, the mother and the fetus, and serves as an intermediary between maternal and fetal circulations. It is not merely a passive barrier between the maternal and fetal circulations but has many physiological functions, including the exchange of respiratory gasses, metabolites, nutrients, and waste products as well as the production of hormones and the metabolism of xenobiotics [1].

The usual human term placenta is about $22 \mathrm{~cm}$ in diameter and 2.0 to $2.5 \mathrm{~cm}$ thick. It generally weighs about $475 \mathrm{~g}$. However, measurements can vary considerably [2]. Placentas with less than $2.5 \mathrm{~cm}$ thickness are associated with intrauterine growth retardation (IUGR) of the fetus [3]. Placentas more than $4 \mathrm{~cm}$ thick have an association with maternal diabetes mellitus, fetal hydrops (of both immune and nonimmune etiology), and intrauterine fetal infections [4]. A welldeveloped placenta consists of a chorionic plate, which is of embryonic descent and of a basal plate whose essential layer is the decidua, a derivative of the endometrium. Between these two plates, there is a voluminous intervillous space [1].

The examination of normal placentas and most abnormal placentas can be accomplished within one minute after delivery [2]. Universal examination of the placenta in the delivery 
room, with documentation of findings and submission of tissue for pathologic evaluation based on abnormal appearance or certain clinical indications, is a standard medical practice [5].

ALP, a membrane biomarker and a moderator of cleavage in DNA, improves transport across cell membranes, which causes the dissociation of adenosine triphosphate (ATP) to adenosine diphosphate (ADP) and inorganic phosphate. This makes extra energy available for catabolic and anabolic processes [6]. It is also known that ALP hydrolyzes phosphatic esters in alkaline medium in the form of catalytic proteins found in body tissues $[6,7]$. The human term placenta contains only traces of carbohydrate as reported by Kawasaki et al. [8].

Indications for placental pathologic examination include a poor pregnancy outcome (prematurity, intrauterine growth retardation, prenatal death, and asphyxia), systemic maternal disorders, third-trimester bleeding, and evidence of foetal or maternal infection [5]. Investigations on the influence of smoking on placental morphology and function have begun to define the pathophysiological mechanisms involved. Ultrastructural changes including cytotrophoblast hyperplasia, thickening of the trophoblast basement membrane, and decreased capillary density at the terminal villi are believed to contribute to reduced placental nutrient and oxygen transfer $[9,10]$.

Although placental weight and volume at delivery may be an important determinant of birth weight, both the pattern and rate of growth of the placenta throughout pregnancy are expected to be important contributors [7]. Incongruous controversial staining results are a common phenomenon in the placenta; methodical investigations are important to prevent researchers from obtaining misleading results [7].

Apoptosis is a physiologic form of cell death and is important in the control of cell population. It plays key roles in the regulation of various physiological and pathological conditions, including vertebrate development, ovarian follicular atresia, immune disorders, and cancers [7, 11]. Apoptosis is present in the placenta throughout gestation, increases near the end of gestation, and is believed to be physiologically important for normal placental growth and development [1214]. Increased trophoblast apoptosis has been documented in placentae growth-restricted foetuses, and maternal smoking is associated with decreased placental apoptosis at term [15, 16].

\section{Materials and Methods}

2.1. Time Frame. The fieldwork for this study was conducted during the period 2008-2012 at Dolu Specialist Hospital, Mafoluku-Oshodi, Lagos. A cross-sectional and follow-up approach was used [17].

2.2. Specimen Collection. Human term placentas were collected at the point of delivery by a consultant obstetrician and gynaecologist in our presence after the consent of the patient has been sought. Immediately after delivery, the cord was clamped and membranes were then carefully trimmed after which each placenta was weighed. $3 \mathrm{~cm} \times 2.5 \mathrm{~cm}$ pieces of placenta (chorionic villous) were cut along its lateral diameter (3 o'clock position) after the membranes have been trimmed. A total of 48 normal placentas and 15 placentas of known intrauterine growth retardation cases were used for this study. IUGR cases were confirmed on the basis of ultrasound follow-up and diagnosis.

Approximately $26 \mathrm{~mm}$ piece of placenta was excised from the peripheral margin, midway between the maternal/foetal membrane for the normal control (Group A) and that of growth retarded tissues (Group B), after proper identification of the appropriate anatomical landmarks.

Before fixing the specimen, adequate amounts of formal saline (at least 10 times as much formal saline as placental tissue/volume) were used so that the fixative will overflow the tissue and allow proper fixation.

The morphology of the villi was observed; concentrated cell foci of syncytial knots and capillaries (sections) were counted and observed with $\times 150$ and $\times 600$ magnifications.

2.3. Quantitative Histochemical Assay. The tissues placental cuts $(3 \mathrm{~cm} \times 2.5 \mathrm{~cm})$ were weighed immediately, homogenized with an electronic blender before the use of a mortar and pestle in a cold $0.5 \mathrm{M}$ sucrose solution. A solution of $10 \%$ (w/v) tissue concentration was made Matsubara et al. [7] The homogenate was centrifuged at $1000 \mathrm{rpm}$ for 5 minutes, after which the supernatants were collected with Pasteur pipette for the assay [18] adopting standard spectrophotometric procedures $[19,20]$. ALP kit used was purchased from Quimica Clinica Aplicada, Spain.

2.4. Histopathology. Specimens were placed in labelled sterile bottles and immersed in $10 \%$ formal saline for 48 hours. These specimens were later processed for paraffin embedding; $3 \mu \mathrm{m}$ thick sections were made on rotary microtome for haematoxylin and eosin staining method [21].

2.5. Statistical Analysis. Statistical analysis was accomplished using the one-way analysis of variance (ANOVA) on the statistical software SPSS, version 17. Values were reported as mean \pm SEM (standard error of the mean). The $P$ values below 0.05 were considered as significant.

\section{Results}

Histological observation showed that the basal plate (decidual tissue) had large number of cells with basophilic nuclei. There were variations in regard to tissue brightness (for collagen), but the morphological characteristics appeared the same among cells with different cytoplasmic darkness.

At lower magnification placenta from a full term foetus, Figure 1 illustrates huge numbers of villi in various planes of the section and varying in diameter from large main stem villi to very small terminal branch villi. The villous pattern is much more highly developed and the average villous diameter is much smaller, reflecting the extensive branching growth of the villi as the placenta enlarges. Note the large blood vessels within in the largest villi. 


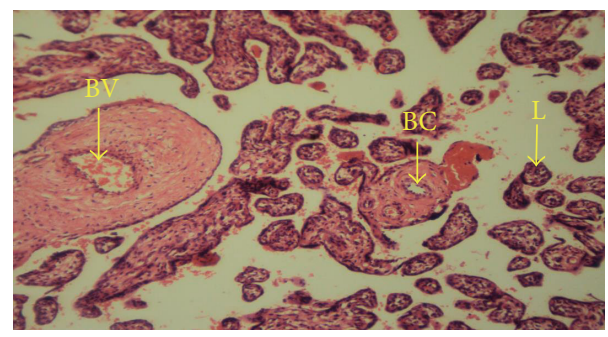

FIGURE 1: H\&E, $\times 150$, showing the midsection through the villous chorion. BV: blood vessel, L: lacunae, BC: blood capillary, and normal term placenta (Group A).

A classical feature of the term placenta is the syncytial knot, where syncytiotrophoblast nuclei are aggregated together in clusters leaving zones of thin cytoplasm devoid of nuclei. The syncytiotrophoblast covered the terminal villi and the surface of the basal plate. At some places, the syncytial layer was discontinuous (Figure 2). Syncytial knots were recognized as uneven distribution of nuclei within syncytial trophoblast (Figure 3). In the deep part of the basal plate in IUGR placenta, there was uteroplacental vein surrounded by extravillous cytotrophoblast in the left lower quadrant (Figure 4).

The level of activity of alkaline phosphatase (ALP) was higher $(556.16 \pm 0.81)$ in the growth retarded placenta group (Group B) when compared with $(39.48 \pm 0.92)$ the normal term placenta group (Group A). This difference was statistically significant at $P<0.05$, even at $P<0.00$ (Table 1 and Figure 5).

\section{Discussion}

The trophoblast is reduced to a thin layer of syncytiotrophoblast only and the capillaries tend to be located in the periphery of the core. The diffusion barrier between maternal and fetal circulations comprises five layers, namely, trophoblast, trophoblast basement membrane, villous core supporting tissue, capillary endothelial basement membrane, and endothelium. In many cases, fetal capillaries are so close to the trophoblast that their basement membranes fuse, reducing the diffusion barrier to only three layers. Diverse number of stimuli and mediators are likely to contribute to the observed injury to the chorioallantoic villi but oxidative stress is high on the list as an injurious agent [22]. A recent landmark report shows that the placentas of pregnancies with IUGR exhibit overt signs of oxidative stress, with reduced protein translation and reductions in key signaling proteins pathways [23]. Greater injury of the villous trophoblast layer as described here will without doubt reduce the functional mass of the syncytiotrophoblast in microsomic and growth retarded so as to mediate nutrient transport between the mother and foetus. This is the main reason for the stunted growth as proven in Figures 2 and 4, Table 1, and Figure 5.

Without epithelial injury, change in the normal balance of proliferation, differentiation, and possibly apoptosis during the villous trophoblast life cycle will also limit the functional mass of placental trophoblastic-surface villi. Rise in

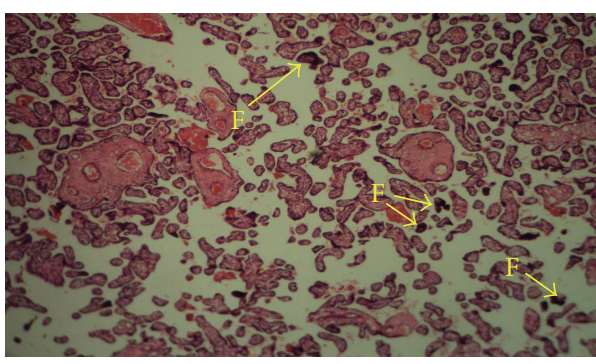

Figure 2: H\&E, $\times 150$, arrows point to some fibrin $(F)$ containing fibrinoid deposits on the surface of the villi where there is discontinuity in the syncytiotrophoblast layer, IUGR placenta (Group B).

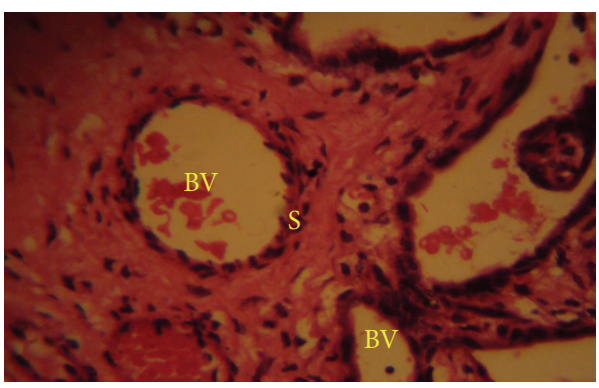

FIGURE 3: H\&E, $\times 600$, circumferential syncytial knot $(S)$, concentration observed around blood vessel (BV), and normal term placenta (Group A).

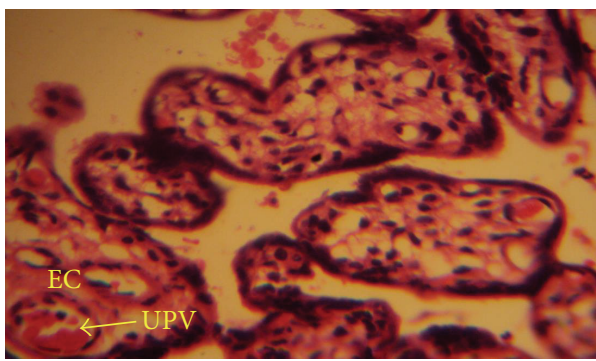

FIgURE 4: H\&E, $\times 600$, note the uteroplacental vein (UPV) surrounded by extravillous cytotrophoblast (EC), IUGR placenta (Group B).

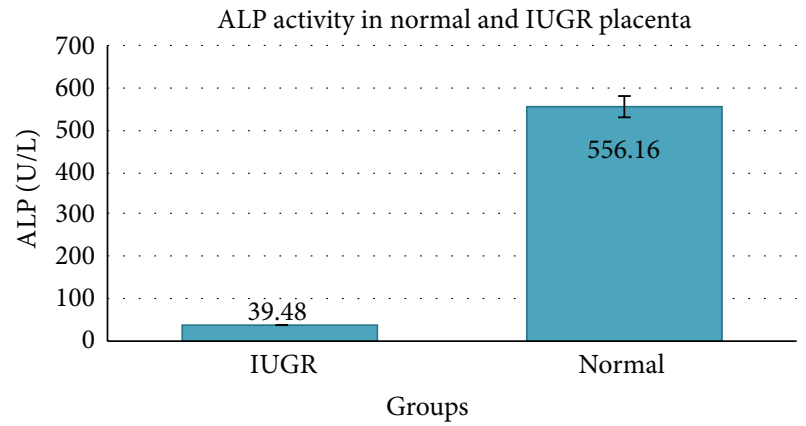

FIGURE 5: Level of alkaline phosphatase activity. 
TABLE 1: Alkaline phosphatase activity in normal term and IUGR placenta tissues.

\begin{tabular}{lcc}
\hline Category & ALP (U/L) & $P$ value \\
\hline Normal term placenta (Group A) & $39.48 \pm 0.92^{*}$ & \multirow{2}{*}{0.00} \\
IUGR placenta (Group B) & $556.16 \pm 0.81^{*}$ & \\
\hline
\end{tabular}

${ }^{*}$ Level of significance $(P<0.05)$.

cellular cytotrophoblast compensatory proliferation in IUGR is not recorded despite apoptic turnover of the trophoblast layer. Apparent microscopic injury has functional effects on placental permeability; large molecular weight compounds will be restricted from passing between the maternal and foetal layers, that is, without intervention of cytoplasmic syncytiotrophoblast. Apoptosis is regulated at many levels. Cultured trophoblasts exposed to hypoxia showed a compensatory regulation of enzyme activity $[24,25]$.

Our study has demonstrated the overall increase of syncytial knots being significantly higher in the syncytial membrane (Figure 3). There are a number of important factors that should be considered in interpretation and analysis of these results. Syncytial knots formation is upregulated by intraplacental hypoxia and downregulated by increasing intraplacental oxygen levels [26].

A strong activity of ALP was observed in growth retarded placental tissues (Table 1 and Figure 5) which were higher than what was observed in the normal term placental tissues. It is not quite clear why alkaline phosphatase levels become elevated in pregnancy; Wilshaw and Moloney [27] suggested that the enzyme is involved in glycogenesis, to meet demands of intrauterine development and nucleic acid formation.

It is conceivable then that higher ALP levels in growth retarded placental specimen are associated with greater need for glycogen synthesis and nucleic acid synthesis in the pregnant mother in order to meet the demands of fetal development in growth restricted cases. ALP activity plays an essential role in nutrient (glucose and albumin) supply to the fetus.

Activation of alkaline phosphate by $\mathrm{Mg}^{2+}$ and its inhibition by $\mathrm{Zn}^{2+}$ in term human placenta support the findings of Sugiura et al. [28] and Matsubara et al. [7]. The present study is in agreement with that of placenta-like alkaline phosphatases from human osteosarcoma cells [29], but in contradiction with other works [30].

Clarifying the role of complement activations in pregnancies complicated by IUGR and in placental dysfunction generally will lead to new approaches to the treatment for IUGR, as therapeutic options to modulate complement receptors and complement activity are on the horizon.

\section{Conclusion}

Histopathological studies of the placenta in IUGR indicate that abnormalities of the maternal spiral arterioles, dysregulated villous vasculogenesis, and abundant fibrin deposition are characteristics in IUGR as reported by Redline [31]. This result leads to the conclusion that disease process which depends on a reduction in the maternal blood affects those parts of the organ furthest from the origin of the blood supply, that is, the periphery of the placenta. In IUGR cases, the terminal villi, syncytial knots, and capillaries were in the central region as opposed to the peripheral region. The precise mechanisms underlying structural, molecular, and cellular aspects during organogenesis only recently have begun to be studied.

Therefore, the study of placental cells after gestation can provide important information about the pathophysiology of many syndromes that occur in pregnancy.

\section{Conflict of Interests}

The authors declare that there is no conflict of interests regarding the publication of this paper.

\section{References}

[1] J. Zheng, Recent Advances in Research on the Human Placenta, InTech, 1st edition, 2012.

[2] J. F. Yetter III, "Examination of the placenta," The American Family Physician, vol. 57, no. 5, pp. 1045-1054, 1998.

[3] K. Benirschke and P. Kaufmann, "Anatomy and Pathology of the placental membranes," in The Pathology of The Human Placenta, K. Benirschke and P. Kaufmann, Eds., pp. 281-334, Springer, New York, NY, USA, 2000.

[4] K. Benirschke and P. Kaufmann, Pathology of the Human Placenta, Springer, New York, NY, USA, 2nd edition, 1990.

[5] S. G. Driscoll and C. Langston, "College of American Pathologists Conference XIX on the examination of the placenta: report of the working group on methods for placental examination," Archives of Pathology and Laboratory Medicine, vol. 115, no. 7, pp. 704-708, 1991.

[6] R. K. Murray, D. K. Granner, P. A. Mayes, and V. W. Rodwell, Harpers Illustrated Biochemistry, McGraw-Hill, New York, NY, USA, 26th edition, 2003.

[7] S. Matsubara, T. Takayama, R. Iwasaki, A. Izumi, T. Watanabe, and I. Sato, "Chorion laeve trophoblasts of preeclamptic fetal membranes: histochemically detectable enzyme activities do not change at a subcellular level," European Journal of Histochemistry, vol. 45, no. 3, pp. 211-217, 2001.

[8] H. Kawasaki, Y. Akagi, and T. Miyamoto, "Isolation and some characteristics of placental alkaline phosphatase," Kurume Medical Journal, vol. 24, no. 1, pp. 7-18, 1977.

[9] K. T. Shiverick and C. Salafia, "Cigarette smoking and pregnancy. I: ovarian, uterine and placental effects," Placenta, vol. 20, no. 4, pp. 265-272, 1999.

[10] K. Benirschke and P. Kaufmann, Pathology of the Human Placenta, Springer, New York, NY, USA, 5th edition, 2006.

[11] J. Kim, Y. Yoon, and B. K. Tsang, "Involvement of the Fas/Fas ligand system in p53-mediated granulosa cell apoptosis during follicular development and atresia," Endocrinology, vol. 140, no. 5, pp. 2307-2317, 1999.

[12] S. C. Smith, P. N. Baker, and E. M. Symonds, "Placental apoptosis in normal human pregnancy," The American Journal of Obstetrics and Gynecology, vol. 177, no. 1, pp. 57-65, 1997.

[13] A. Gruslin, Q. Qiu, and B. K. Tsang, "X-linked inhibitor of apoptosis protein expression and the regulation of apoptosis during human placental development," Biology of Reproduction, vol. 64 , no. 4, pp. 1264-1272, 2001. 
[14] B. Huppertz, "The anatomy of the normal placenta," Journal of Clinical Pathology, vol. 61, no. 12, pp. 1296-1302, 2008.

[15] S. C. Smith, P. N. Baker, and E. M. Symonds, "Increased placental apoptosis in intrauterine growth restriction," The American Journal of Obstetrics and Gynecology, vol. 177, no. 6, pp. 1395-1401, 1997.

[16] H. R. C. Marana, J. M. Andrade, G. A. Martins, J. S. Silva, M. A. Sala, and S. P. Cunha, "A morphometric study of maternal smoking on apoptosis in the syncytiotrophoblast," International Journal of Gynecology and Obstetrics, vol. 61, no. 1, pp. 21-27, 1998.

[17] E. Mansour, A. N. Eissa, L. M. Nofal, I. Kharboush, A. Wagida, and I. Sallam, "Incidence and factors leading to low birth weight in Egypt," International Pediatrics, vol. 17, no. 4, pp. 223-230, 2002.

[18] A. L. Babson, S. J. Greeley, C. M. Coleman, and G. E. Phillips, "Phenolphthalein monophosphate as a substrate for serum alkaline phosphatase," Clinical Chemistry, vol. 12, no. 8, pp. 482490, 1966.

[19] W. C. Gamberino, D. A. Berkich, C. J. Lynch, B. Xu, and K. F. LaNoue, "Role of pyruvate carboxylase in facilitation of synthesis of glutamate and glutamine in cultured astrocytes," Journal of Neurochemistry, vol. 69, no. 6, pp. 2312-2325, 1997.

[20] E. Lieth, K. F. LaNoue, D. A. Berkich et al., "Nitrogen shuttling between neurons and glial cells during glutamate synthesis," Journal of Neurochemistry, vol. 76, no. 6, pp. 1712-1723, 2001.

[21] P. Ehrlich, "Hamatoxylinlösung," Z Wiss Micr, vol. 3, p. 150, 1886.

[22] T. Hung, J. N. Skepper, D. S. Charnock-Jones, and G. J. Burton, "Hypoxia-reoxygenation: a potent inducer of apoptotic changes in the human placenta and possible etiological factor in preeclampsia," Circulation Research, vol. 90, no. 12, pp. 12741281, 2002.

[23] H. Yung, S. Calabrese, D. Hynx et al., "Evidence of placental translation inhibition and endoplasmic reticulum stress in the etiology of human intrauterine growth restriction," The American Journal of Pathology, vol. 173, no. 2, pp. 451-462, 2008.

[24] R. Levy, S. D. Smith, K. Chandler, Y. Sadovsky, and D. M. Nelson, "Apoptosis in human cultured trophoblasts is enhanced by hypoxia and diminished by epidermal growth factor," The American Journal of Physiology: Cell Physiology, vol. 278, no. 5, pp. C982-C988, 2000.

[25] A. E. P. Heazell, H. A. Lacey, C. J. P. Jones, B. Huppertz, P. N. Baker, and I. P. Crocker, "Effects of oxygen on cell turnover and expression of regulators of apoptosis in human placental trophoblast," Placenta, vol. 29, no. 2, pp. 175-186, 2008.

[26] G. J. Burton, "On oxygen and placental villous development: origins of fetal hypoxia," Placenta, vol. 18, no. 8, pp. 625-626, 1997.

[27] E. Wilshaw and W. C. Moloney, "Histochemical and biochemical studies on leukocyte alkaline phosphatase activity," Blood, vol. 10, no. 11, pp. 1120-1131, 1955.

[28] M. Sugiura, H. Kazuyaki, I. Shiro, S. Hiroshi, and O. Toshitsugu, Chemical andPharmaceutical Bulletin, vol. 25, p. 653, 1977.

[29] I. Singh, K. Y. Tsang, and W. S. Blackemove, "Placenta-like alkaline phosphatases from human osteosarcoma cells," Cancer Research, vol. 38, pp. 193-198, 1978.

[30] S. Matsubara, T. Tamada, and T. Saito, "Ultrastructural localization and cytochemical characteristics of human placental ADP-degrading activity in normal and preeclampti pregnancy," Trophoblast Research, vol. 9, pp. 121-129, 1997.
[31] R. W. Redline, "Placental pathology: a systematic approach with clinical correlations," Placenta, vol. 29, supplement, pp. 86-91, 2008 . 

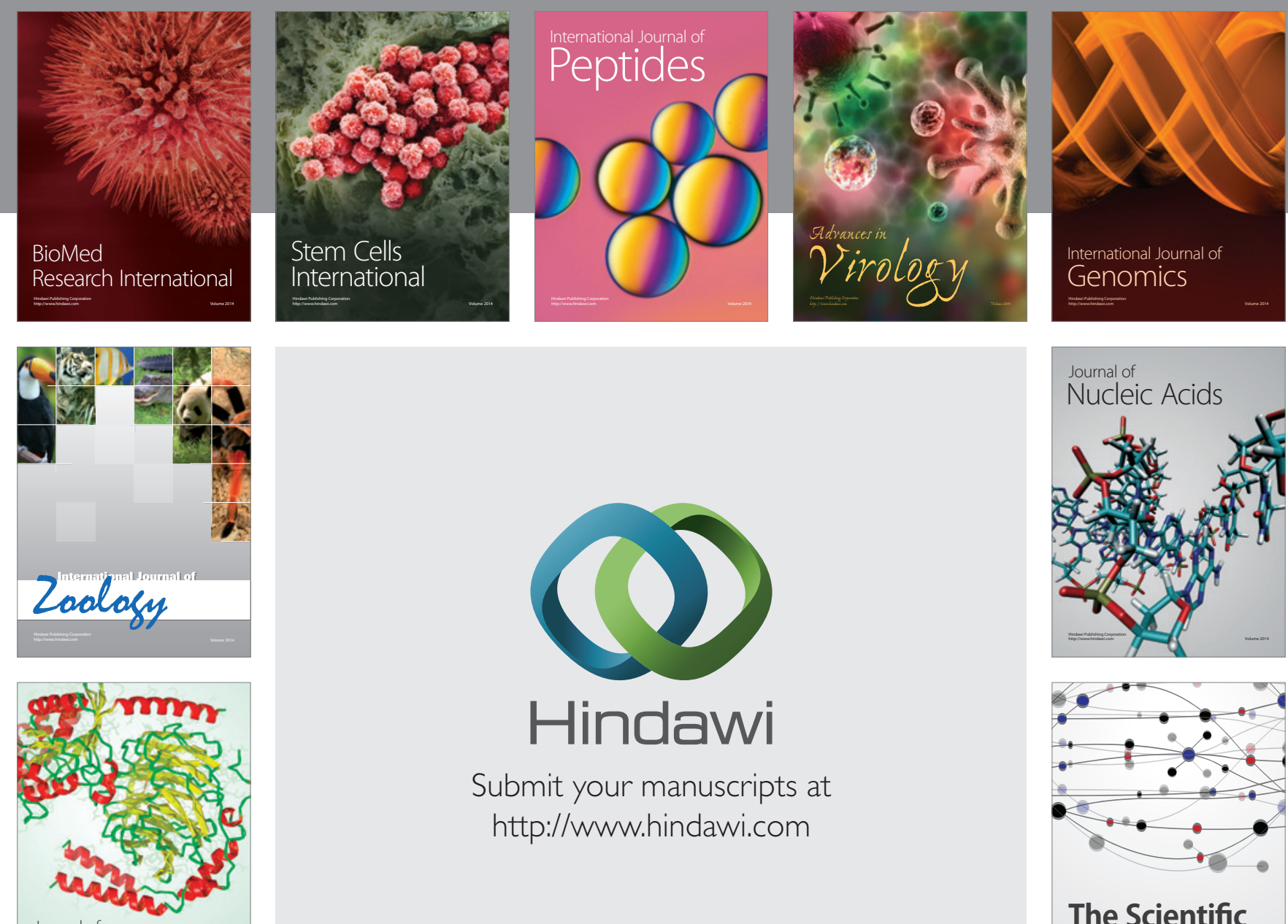

Submit your manuscripts at

http://www.hindawi.com

Journal of
Signal Transduction
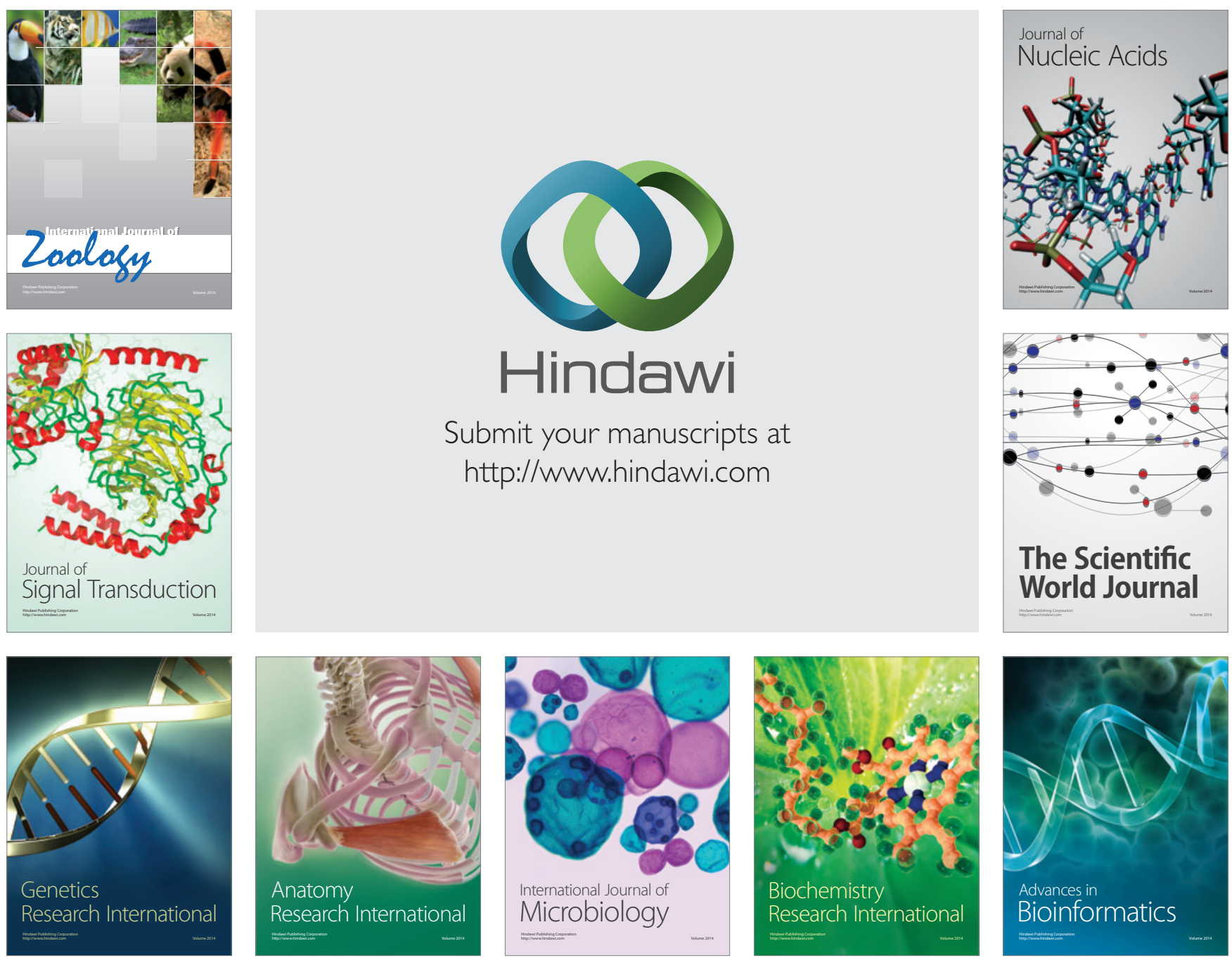

The Scientific World Journal
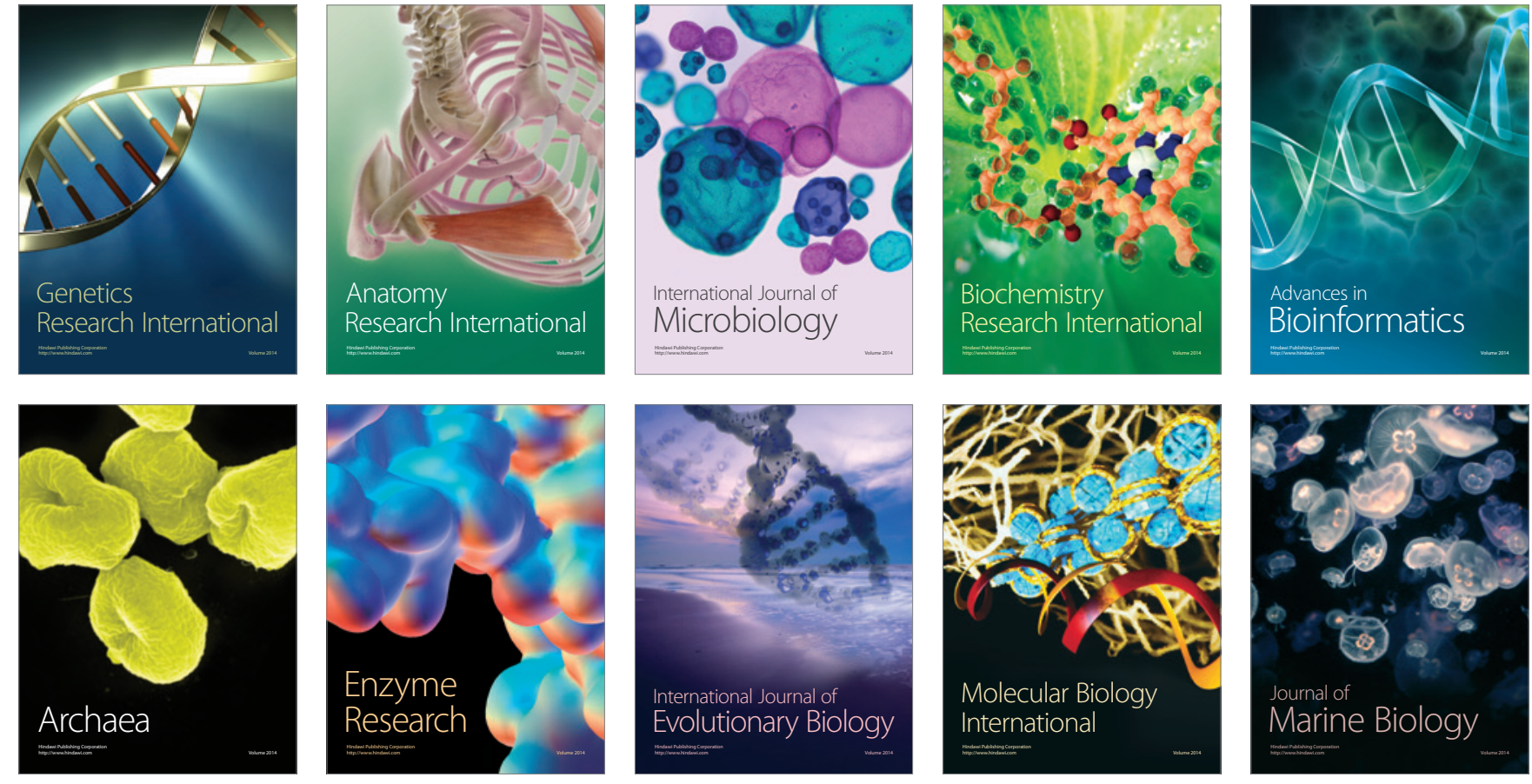